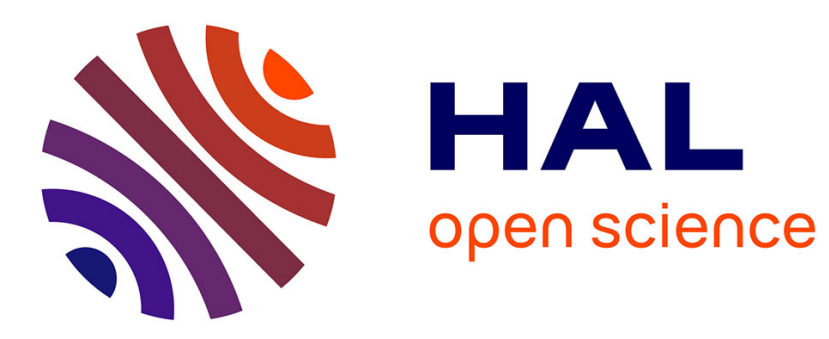

\title{
Numerical calculation of the odd part of the texture function
}

\author{
C. Esling, E. Bechler -Ferry, H.-J. Bunge
}

\section{To cite this version:}

C. Esling, E. Bechler -Ferry, H.-J. Bunge. Numerical calculation of the odd part of the texture function. Journal de Physique Lettres, 1981, 42 (6), pp.141-144. 10.1051/jphyslet:01981004206014100 . jpa00231893

\section{HAL Id: jpa-00231893 https://hal.science/jpa-00231893}

Submitted on 1 Jan 1981

HAL is a multi-disciplinary open access archive for the deposit and dissemination of scientific research documents, whether they are published or not. The documents may come from teaching and research institutions in France or abroad, or from public or private research centers.
L'archive ouverte pluridisciplinaire HAL, est destinée au dépôt et à la diffusion de documents scientifiques de niveau recherche, publiés ou non, émanant des établissements d'enseignement et de recherche français ou étrangers, des laboratoires publics ou privés. 


\title{
Numerical calculation of the odd part of the texture function
}

\author{
C. Esling $\left({ }^{*}\right)$, E. Bechler -Ferry $\left({ }^{*}\right)$ and H.-J. Bunge $\left({ }^{* *}\right)$ \\ (*) Laboratoire de Métallurgie Structurale, Ile du Saulcy, 57000 Metz, France \\ $\left({ }^{* *}\right)$ Institut für Metallkunde und Metallphysik der TU Clausthal, F.R.G.
}

(Reçu le 11 juin 1980, révisé le 30 janvier 1981, accepté le 2 février 1981)

\begin{abstract}
Résumé. - Dans une récente note, nous avions proposé une méthode qui permet de déterminer la partie impaire de la fonction de texture à partir des domaines nuls de figures de pôles expérimentales [3].

Afin de prouver la validité de cette méthode, des calculs numériques ont été effectués à partir d'une fonction de texture théorique du type gaussienne; ensuite, la méthode a été appliquée pour déterminer la fonction de texture totale d'un échantillon de cuivre laminé.
\end{abstract}

\begin{abstract}
In a recent letter a method was proposed how to determine the odd part of the texture function from the null domains of experimental pole figures [3].

In order to prove the validity of this method, numerical calculations have been done from a theoretical texture function of a gaussian type; then, the method has been applied to determine the complete texture function of a rolled copper sample.
\end{abstract}

The orientation distribution function ODF of crystallites in a polycrystalline sample can be calculated from experimental pole figures by a series expansion method [1]

$$
f(g)=\sum_{l=0(1)}^{L} \sum_{m=-l}^{+l} \sum_{n=-l}^{+l} C_{l}^{m n} T_{l}^{m n}(g) .
$$

In the case of centrosymmetric crystals or by virtue of Friedel's law $[2,3]$ the odd part of this series $f^{\mathrm{a}}(g)$ does not contribute to the experimental pole figures. Hence, it cannot be determined from pole figure measurements as can the even part $f^{\mathrm{s}}(g)$. Nevertheless, there may be some information on the odd part contained in pole figures, if the pole figures and hence the ODF contain zero ranges $Z^{0}$. From the general positivity condition

$$
f(g)=f^{\mathrm{s}}(g)+f^{\mathrm{a}}(g) \geqslant 0
$$

it follows

$$
f^{\mathrm{a}}(g)=-f^{\mathrm{s}}(g) \quad \forall g \in \mathrm{Z}^{0} .
$$

Since $f^{\mathrm{s}}(g)$ is known by classical methods, $f^{\mathrm{a}}(g)$ is known in $Z^{0} . f^{\mathrm{a}}(g)$ may then be approximated in $Z^{0}$ by a series equation (1) (with odd terms only). This series defines an approximation to $f^{\mathrm{a}}(g)$ in the whole orientation space. Two different approximation conditions have been proposed. In the first method of reso- lution [3], which may be called "global method", the even part $f^{\mathrm{s}}(g)$ in equation (3) is made up for an odd series which globally contains all the $C_{l}^{m n}$ coefficients of odd degree; and this, from the degree $l_{0}$ at which appear the first odd coefficients $\left(l_{0}=9\right.$ in the case of cubic symmetry), up to the maximal degree $L_{1}$ in the series expansion of $f^{\text {a }}(g)$ :

$$
\int_{\mathrm{z}_{1}}\left(-f^{\mathrm{s}}(g)-\sum_{l=l_{0}}^{L_{1}} \Delta f_{l}(g)\right)^{2}=\operatorname{Min} .
$$

$\Delta f_{l}$ represents the contribution, in $f^{\mathrm{a}}(g)$, of the odd degree $l$.

In the second method of resolution [4], which may be called "iterative method", the minimization equation (4) is realized in a recurring way :

$$
\int_{\mathrm{z}_{0}}\left(-f^{\mathrm{s}}-\sum_{\lambda=l_{0}}^{l-2} \Delta f_{\lambda}-\Delta f_{l}\right)^{2}=\text { Min . }
$$

Thus, for the determination, by the condition equation (5), of the odd coefficients of a given $l$ degree, the known part of the texture function, $f^{\prime}(g)$, is completed with the odd part already determined in the previous steps, up to the degree $l-2$; the iterative calculations can be stopped at the maximal degree $L_{1}$ of the odd series $f^{a}(g)$. Both approximation conditions will work the better the larger the zero range $Z^{0}$ is. The applicability of the method thus depends on 
the actual shape of the ODF, especially on the size of the zero range $Z^{0}$.

1. Theoretical texture function of a gaussian type. To convice ourselves by the validity of the zero range method, we tested it with a theoretical model-function. We defined a gaussian type distribution function corresponding to the $\{011\}\langle 211\rangle$ component, typical of the rolling texture of brass; this orientation had been previously chosen by Matthies and Pospiech [5] in a recent work, which aimed to show the effect of the odd part of the texture function. In the case of this model function, we could calculate the even and the odd coefficients $C_{l}^{m n}$ of the texture function equation (1). On the other hand, these even coefficients have been used to calculate four pole figures corresponding to the diffraction of the planes (111), (200), (220) and (311). Out of these pole figures the null domain $Z^{0}$ in the orientation space could be determined and the odd coefficients were then calculated by the zero range method.

The obtained results are concisely presented in the two first figures. The odd texture coefficients calculated by the global method are in a striking agreement with the expected "theoretical» coefficients; the mean values of the relative differences $\Delta C_{l} /\left|C_{l}\right|$ are less than $2 \%$ (Fig. 1). The iterative method leads to similar results, although the obtained odd coefficients are systematically smaller than those calculated by the first method (Fig. 2), which only will be considered in the following. Figure 1 shows that in the case of a gaussian function, the mean values of the odd coefficients take on as high values as the mean values of the even ones. Indeed, the respective convergence curves of the odd and even order coefficients cross each other.

2. Calculations out of experimental pole figures. The method has been applied to the rolling texture of $95 \%$ cold rolled copper of which the (111), (200), (220) and (311) pole figures had been determined by

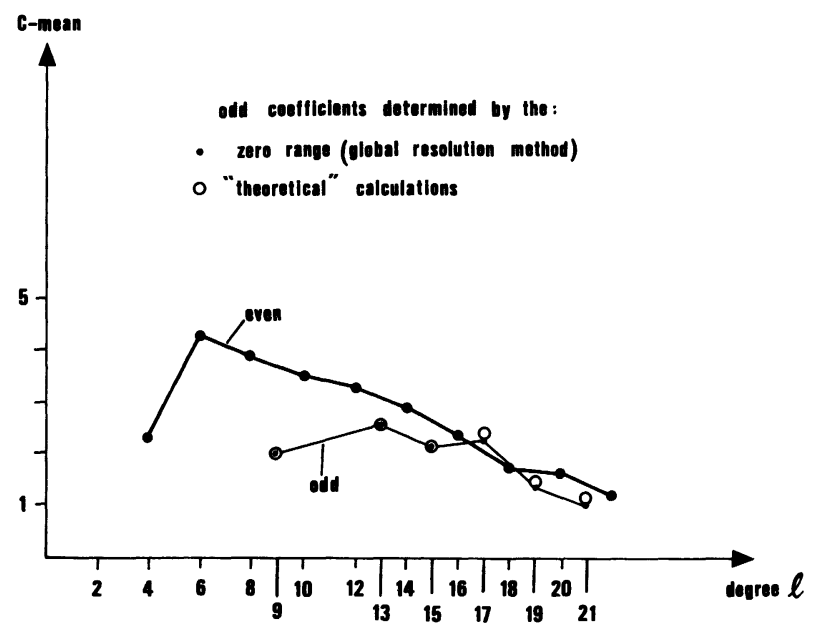

Fig. 1. - Gaussian model-function : mean values of the even and odd $C$-coefficients.

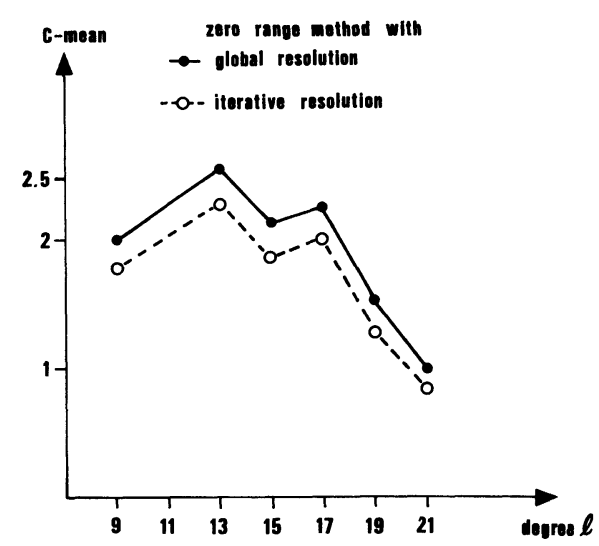

Fig. 2. - Gaussian model-function : mean values of the odd coefficients obtained by the two approximations of the zero range method (global and iterative resolution).

neutron diffraction in steps of $2.5^{\circ} \times 2.4^{\circ}$. The zero range $Z_{(h k l)}^{0}$ has been chosen by $N \leqslant 2 \sqrt{N_{(h k l)}^{\mathrm{b}}}$ where $N$ is the number of counts already corrected from the background scattering $N_{(h k l)}^{\mathrm{b}}$. The (111) pole figure is shown in figure 3 . From the zero ranges of the four pole figures the zero range $Z^{0}$ of the ODF was determined. In steps of $5^{0} \times 5^{0} \times 5^{0}$ all orientations $g$ were tested whether or not there was an $(h k l)$ pole falling into the zero range $Z_{(h k l)}^{0}$ of the corresponding pole figure. As an example the section $\varphi_{2}=15^{\circ}$ of the so-obtained zero range is shown in figure 4 . The whole zero range amounts to about $2 / 3$ of all orientation points in the whole orientation space (Euler space). The calculation of the even part of the texture function was carried out by the classical method up to $L_{\text {even }}=34$. The coefficients $C_{l}^{m n}$ of the odd part were then determined by the two approximation methods up to $L_{\mathrm{odd}}=21$. The results of the two methods are similar so that we present only, in the following, the numerical results of the global resolution method, the results of which have been

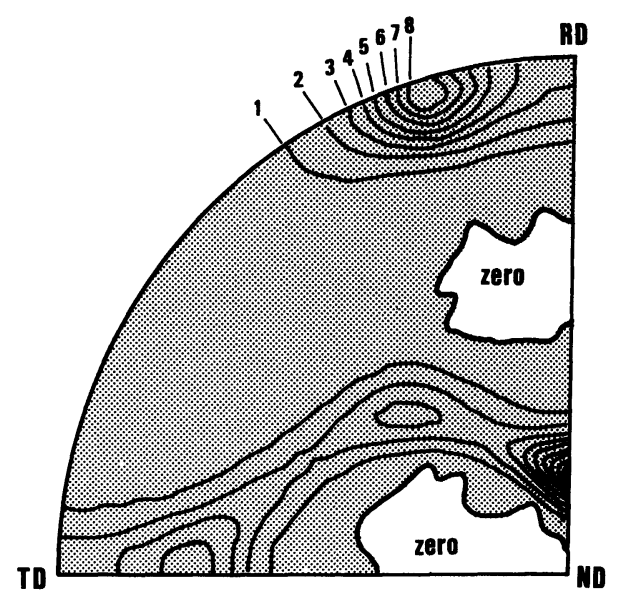

Fig. 3. - (111)-normalized pole figure measured by neutron diffraction in steps of $2.5^{\circ} \times 2.4^{\circ}$. The zero range $Z_{(111)}^{0}$ is indicated; the levels are multiples of random distribution (copper sample). 


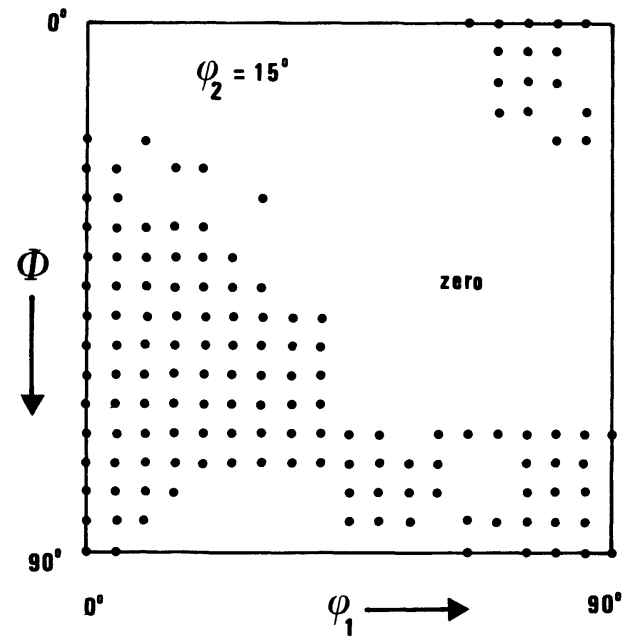

Fig. 4. - The section $\varphi_{2}=15^{\circ}$ of the zero range $\mathrm{Z}^{0}$ in the orientation space, for the rolled copper sample.

the most satisfying. In figure 5 the mean values of the coefficients $C_{l}^{m n}$ of even and odd order respectively are shown along with the errors of the even coefficients. The odd coefficients turn out to be sensibly smaller than the even ones, although they remain in the same order of magnitude. This was not to be expected beforehand and is thus one of the results

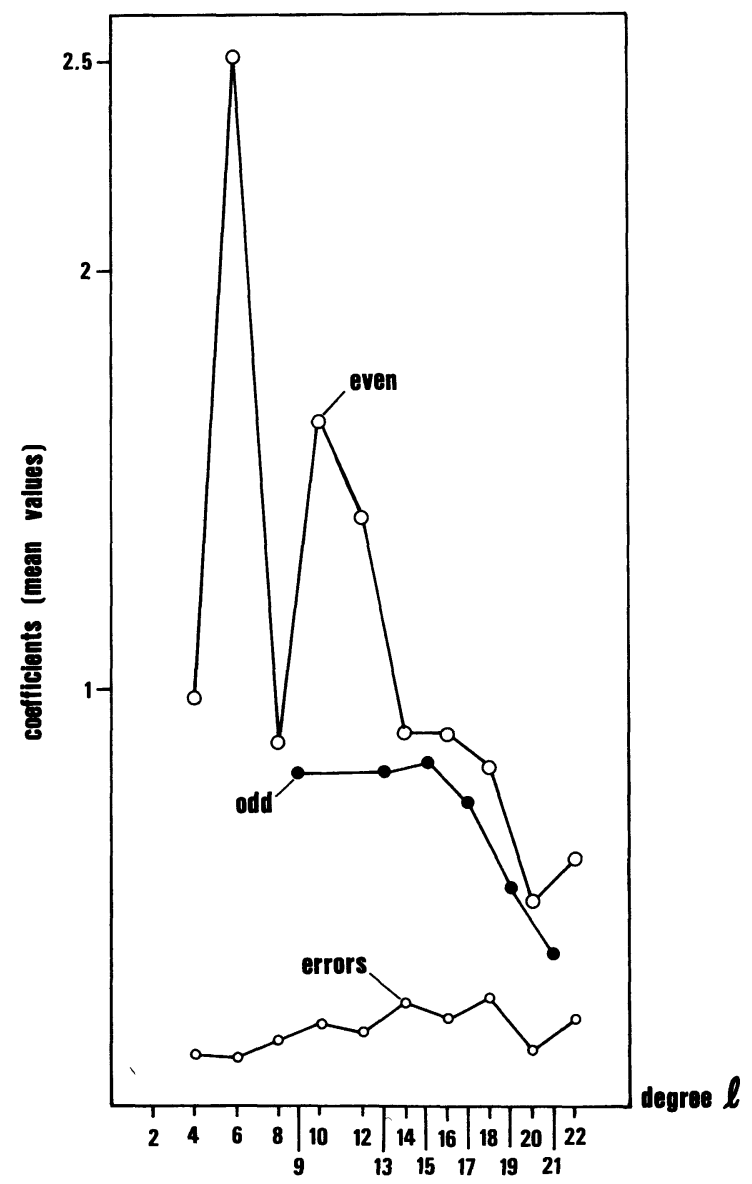

Fig. 5. - Mean values of the coefficients $C_{l}^{m n}$ and the errors $\Delta C_{l}^{m n}$ as function of $l$, for the rolled copper sample.

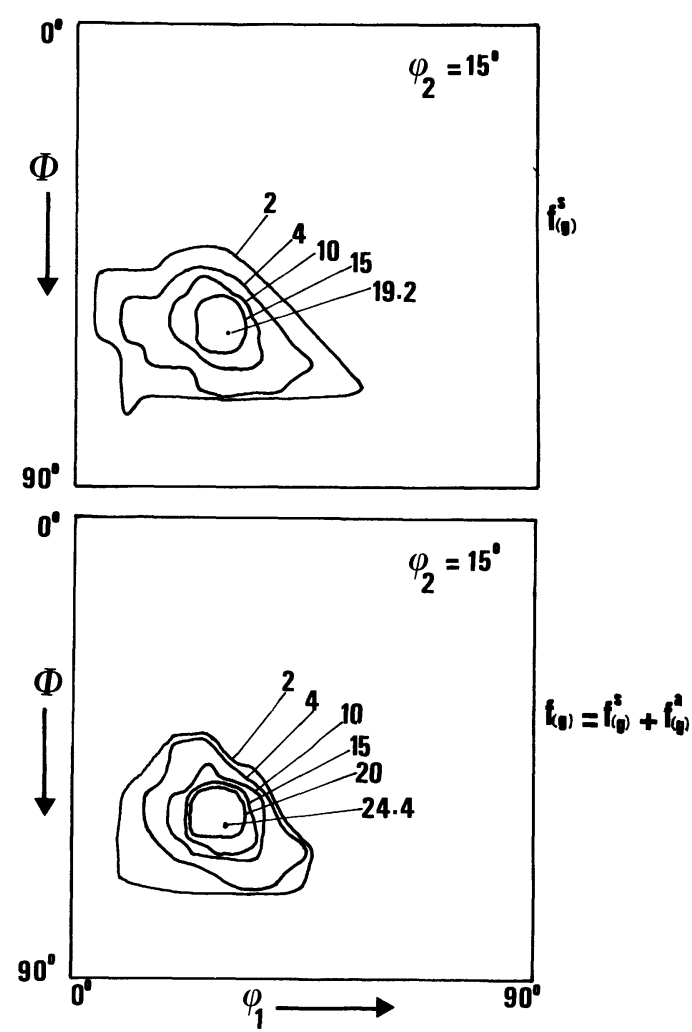

Fig. 6. - The section $\varphi_{2}=15^{\circ}$ of the total texture function and its even part, for the rolled copper sample.

of the present numerical calculation. Indeed, contrary to the case of the gaussian model-function, the convergence curve of the odd coefficients always lays distinctly below the even one. A good convergence of the odd coefficients, like that presented in figure 5 , must be expected a priori in order to be considered as significant, for their contribution to the total texture function. Furthermore, the odd coefficients are in their order of magnitude, markedly higher than the errors of the even coefficients. Thus, the odd part $f^{a}(g)$ of the texture function, although it is lower than the even part $f^{\mathrm{s}}(g)$, contributes significantly to the features of the total texture function.

As an example in figure 6 the section $\varphi_{2}=15^{\circ}$ of the total texture function and its even part are shown. It must be emphasized that the contribution of the odd part may be larger in other textures although two other calculations using single orientation measurements which are not inflicted by the blotting out of the odd part [6] also showed smaller values of the odd part, than the even one.

The method used here, based on the positivity condition equation (2) yields the maximum information obtainable from pole figure measurements. On the other hand, it has been suggested to determine the odd part in such a way that the total texture function becomes a Gaussian distribution function [7]. This method is correct if one knows that the total function really is of Gaussian shape. In general, however, this is not the case. The rolling texture of 
the f.c.c. type has been approximated by three Gaussian type components [8], a decomposition which is in no way unique. A different decomposition of the same even part of the function may thus give rise to different odd parts. Hence, the odd part will not be completely predetermined by the even part as it would be implicitly assumed by an unique decomposition into Gaussian components [7].
Acknowledgments. - The authors express their gratitude to :

- Dr. P. I. Welch, Institut für Metallkunde, DClausthal-Zellerfeld, for the use of his pole figure measurements.

- Prof. R. Baro, Director of the Laboratoire de Métallurgie Structurale, F-Metz, for valuable discussions and comments.

\section{References}

[1] Bunge, H. J., Mathematische Methoden der Texturanalyse (Akademie-Verlag, Berlin) 1969.

[2] Matrhies, S., Phys. Status Solidi b 92 (1979) K 135.

[3] Bunge, H. J. and Esling, C., C. R. Hebd. Séan. Acad. Sci. 289B (1979) 163; and Bunge, H. J. and Esling, C., $J$. Physique Lett. 40 (1979) L-627.

[4] Bunge, H. J., Esling, C. and Muller, J., J. Appl. Crystallogr. 13 (1980) $544-554$
[5] Matthies, S. and Pospiech, J., Phys. Status Solidi b 97 (1980) 547.

[6] Wenk, H. R., Wagner, F., Esling, C. and Bunge, H. J., Tectonophysics, in print.

[7] LÜCKE, K., POSPIECH, J. and JURA, J., private communication. [8] PosPiEch, J. and LÜCKe, K., Acta Metall. 23 (1975) 997. 